\title{
EDUCATIONAL NEEDS OF EPILEPTOLOGISTS ABOUT PSYCHIATRIC COMORBIDITIES OF THE EPILEPSIES: A DESCRIPTIVE QUANTITATIVE SURVEY
}

\author{
${ }^{1}$ Marco Mula ${ }^{*}{ }^{2}$ Esper Cavalheiro, ${ }^{3}$ Alla Guekht, ${ }^{4}$ Andres M. Kanner, ${ }^{5}$ Hyang Woon Lee, ${ }^{6}$ Cigdem \\ Ozkara, ${ }^{7}$ Alfredo Thomson, ${ }^{8}$ Sarah J. Wilson
}

1. Atkinson Morley Regional Neuroscience Centre, St George's University Hospitals NHS Foundation Trust; Department of Neuropsychiatry, South West London \& St George's Mental Health Trust; Institute of Medical and Biomedical Sciences, St George's University of London, United Kingdom

2. Department of Neurology and Neurosurgery, Escola Paulista de Medicina/UNIFESP, São Paulo, Brazil

3. Moscow Research and Clinical Center for Neuropsychiatry of the Healthcare Department of Moscow, Pirogov Russian National Research Medical University, Moscow, Russia

4. Comprehensive Epilepsy Center, Department of Neurology, University of Miami, Miller School of Medicine, Miami, USA

5. Epilepsy and Sleep Center, Department of Neurology, Ewha Womans University Mogdong Hospital, Ewha Womans University School of Medicine and Ewha Medical Research Institute, Seoul, South Korea

6. Department of Neurology, Medical Faculty, Istanbul University Cerrahpasa, Istanbul, Turkey

7. Institute of Neurosciences at Favaloro University and Institute of Cognitive and Behavioural Neurology (INECO), Buenos Aires, Argentina

8. Melbourne School of Psychological Sciences, The University of Melbourne, and Comprehensive Epilepsy Program, Austin Health, Melbourne, Australia

\footnotetext{
* Correspondence: Dr Marco Mula MD PhD, Atkinson Morley Regional Neuroscience Centre, St George's University Hospitals NHS Foundation Trust, Blackshaw Road, London SW17 0QT, United Kingdom; Tel: +442087254107; FAX: +442087254591; Email: mmula@sgul.ac.uk
} 


\section{ABSTRACT}

Aim: Psychiatric disorders are relatively frequent comorbidities in epilepsy and they have an impact on morbidity, mortality and quality of life. This is a report from the Task Force on Education of the ILAE Commission on Neuropsychiatry based on a survey about educational needs of epileptologists regarding management of the psychiatric comorbidities of epilepsy.

Methods: The Task Force designed a quantitative questionnaire to survey the self-perceived confidence of child and adult epileptologists and psychiatrists in managing major psychiatric comorbidities of epilepsy to identify (1) critical areas of improvement from a list of skills that are usually considered necessary for effective management of these conditions, and (2) the preferred educational format for improving these skills.

Results: A total of 211 respondents from 35 different countries participated in the survey. Confidence and usefulness scores suggest that responders would most value education and training in the management of specific clinical scenarios. Child neurologists identified major Axis I disorders like mood and anxiety disorders, while adult neurologists identified attention deficit hyperactivity disorder, intellectual disabilities and autistic spectrum disorder as key areas. Both adult and child neurologists identified screening skills as the priority. Psychiatrists mainly valued specific training in the management of psychiatric complications of epilepsy surgery or psychiatric adverse events of antiepileptic drugs. Sessions during congresses and face-to-face meetings represent the preferred educational format, while e-learning modules and review papers were chosen by a minority of respondents.

Conclusions: Results of this survey identify key areas for improvement in managing the psychiatric comorbidities of epilepsy and suggest specific strategies to develop better training for clinicians involved in epilepsy care.

Key words: epilepsy, education, survey, psychiatric disorders, autism, depression, intellectual disabilities, surgery 


\section{INTRODUCTION}

Epilepsy is now recognized as a disorder of the brain characterized not only by an enduring predisposition to generate epileptic seizures, but explicitly also by the neurobiological, cognitive, psychological, and social comorbidities of this condition ${ }^{1}$. Whilst seizure freedom should represent the ultimate goal when possible, it is now becoming evident that numerous factors determine the quality of life (QoL) of people with epilepsy, with comorbid depression or the adverse effects of medications often constituting stronger predictors of poorer QoL than seizure frequency itself ${ }^{2}$. Even in those in whom remission is achievable, QoL remains poor if psychiatric comorbidities are untreated. Successful integration of people with epilepsy into society is another important goal of epilepsy care. Educational level, intellectual ability, psychological stability, family and social support and employment opportunities, as well as the ability to overcome stigma, transportation and mobility issues are important determinants of successful integration ${ }^{3}$. The combination of these factors influences the life of people with epilepsy and what they consider meaningful ${ }^{4}$.

A lifetime history of psychiatric disorders can be identified in one in three people with epilepsy ${ }^{5}$. Mood and anxiety disorders are the most frequently reported ${ }^{6}$ for both biological and psychosocial reasons. In May 2015, the World Health Assembly approved the WHO Resolution on the Global Burden of Epilepsy which provides a powerful tool for engaging national governments in (1) implementing effective actions to improve medical and social services for people with epilepsy, (2) promoting public awareness about epilepsy, and (3) allocating resources to epilepsy research ${ }^{7}$. This provides a wonderful opportunity to improve epilepsy care and address the global burden of epilepsy so that people with epilepsy can receive timely treatment and benefit from educational and occupational opportunities, free from stigma and discrimination. It is, therefore, evident that epileptologists need to develop multiple clinical skills and be able to organise care plans involving a range of experts and health care professionals in order to address the multiple needs of people with epilepsy.

In 2004, Gilliam et al. reported that only $7 \%$ of U.S. neurologists routinely screen epilepsy patients for depression in their outpatient clinics ${ }^{8}$. Since then, the International League Against Epilepsy (ILAE) has developed a number of documents and initiatives in order to increase the awareness of epileptologists of the importance of identifying and managing psychiatric problems in epilepsy and to provide training and clinical instruments to accomplish this goal. Over time, the ILAE Commissions on Neuropsychiatry have developed consensus guidance documents ${ }^{9}$, supported the dissemination of validated screening instruments for depression like the Neurological Disorders Depression Inventory for Epilepsy (NDDIE) ${ }^{10-15}$ and, in conjunction with the Virtual Epilepsy Academy (VIREPA), offered the on-line course on "Neuropsychiatric aspects of epilepsy" that has been run twice.

The Task Force on Education of the ILAE Commission on Neuropsychiatry was appointed to formulate proposals to address the educational needs of epileptologists about the psychiatric comorbidities of epilepsy. This Task Force report is based on the results of a purpose-developed survey circulated among epileptologists and other healthcare professionals working with people with epilepsy.

\section{METHODS}


The Task Force on Education of the ILAE Commission on Neuropsychiatry designed a quantitative questionnaire to survey the educational needs of epileptologists about managing the major psychiatric comorbidities of epilepsy. First, respondents were asked to provide demographic information including gender, age and job role. Second, respondents were asked questions about their routine practice (i.e. whether they routinely screen for psychiatric comorbidities; reluctance about prescribing psychotropic drugs in patients with epilepsy; whether psychiatrists or clinical psychologists are available in their treatment setting). Respondents were then asked to rate their knowledge/confidence in managing the major psychiatric comorbidities of epilepsy using a 5-point Likert-type scale (1=very good, $5=$ very poor), and to assess the importance of a list of skills that are usually considered necessary for effective management of psychiatric comorbidities (i.e. how to screen, how to diagnose, how to treat, how to use behavioural interventions, how to deal with specific situations such as post-surgical complications or psychiatric adverse events of antiepileptic drugs). Finally, the questionnaire asked respondents about their preferred educational format for improving their clinical skills (i.e. books/textbooks; review papers/peer review material; face-to-face meetings like congresses or symposia; e-learning modules). The questionnaire remained online for 8 months between October 2015 and May 2016. It was freely available and easily accessible. The survey was circulated via the ILAE Regional Chairs, who were asked to send the questionnaire to individual ILAE Chapters for distribution. Completion of the questionnaire was entirely anonymous.

\section{RESULTS}

A total of 211 respondents from 35 different countries participated in the survey (Table 1). Demographic data are presented in Table 2. The majority of respondents comprise adult neurologists/epileptologists, $\quad 14.7 \%$ are child neurologists/epileptologists, $\quad 22.4 \%$ psychiatrists/neuropsychiatrists, and $5.7 \%$ are other healthcare professionals especially epilepsy nurses and some neuropsychologists. In almost $40 \%$ of cases neither psychiatrists nor clinical psychologists form part of the epilepsy team, while one third of respondents work in tertiary epilepsy centres with easy access to both. About $50 \%$ of respondents stated that they routinely screen for psychiatric comorbidities and feel at ease with the prescription of psychotropic medications (e.g. antidepressants or antipsychotics) but 1 out of 4 remain reluctant to use these medications in patients with epilepsy (Table 2).

In general terms, management of psychoses, attention deficit hyperactivity disorder (ADHD), psychiatric complications of epilepsy surgery and autistic spectrum disorder (ASD) are perceived as critical by a large number of clinicians, with almost 1 out of 2 rating individual knowledge/confidence as 'poor' or 'very poor' (Figure 1A). However, looking at individual group ratings, adult neurologists, child neurologists, and psychiatrists show some clear differences (Figure 1B, 1C, 1D). Child neurologists mainly perceive Axis I disorders as critical, such as mood and anxiety disorders and psychoses, with more than $50 \%$ rating their knowledge/confidence as 'poor' or 'very poor', followed by complications of epilepsy surgery (Figure 1B). Conversely, more than $60 \%$ of adult neurologists feel that their knowledge about ADHD and ASD is poor or very poor, and 1 out 3 rated their competence in managing intellectual disabilities and psychiatric complications of epilepsy surgery as 'poor' or 'very poor' (Figure 1C). Among psychiatrists, psychiatric complications of epilepsy surgery 
constitutes the only area rated as 'poor' or 'very poor' in terms of knowledge/confidence, and by only 1 of 5 clinicians (Figure 1D).

Regarding specific skills rated as the most important by respondents (Figure 2), both adult and child neurologists identified screening for major psychiatric comorbidities in outpatient clinics as the priority ( $40 \%$ of child neurologists and one third of adult neurologists). Diagnostic issues and developing clinical skills for specific situations like psychiatric complications of epilepsy surgery are considered a priority by one third of psychiatrists.

Data relating to the preferred educational format indicate that the majority of respondents consider congresses (plenary sessions or symposia) to be most valuable (Figure 3). More than half of adult epileptologists and one third of child neurologists and psychiatrists have chosen this as the preferred format.

\section{DISCUSSION}

This survey identified key areas of improvement in terms of knowledge and development of specific skills for epileptologists regarding management of the psychiatric comorbidities of epilepsy. For the first time, psychiatrists were involved in the process and it was possible to identify specific needs for adult and child neurologists treating patients with epilepsy.

Epileptologists are keen to improve their clinical skills and screening during routine clinical practice seems to be the priority. Most adult neurologists feel inadequate or not skilled enough when dealing with patients with epilepsy and ASD, ADHD or intellectual disabilities in general. Child neurologists are historically better trained in these conditions and thus, usually more adept in their management. A prospective community-based study in children and adolescents with active epilepsy showed that up to $40 \%$ of patients have intellectual disabilities (IDs), one third have ADHD, and around $20 \%$ have ASD ${ }^{16}$. In addition, a community-based survey of more than 1000 adults with epilepsy reported that ADHD-like symptoms are present in 1 out of 5 patients and are associated with depression, anxiety, drug-resistance and poor quality of life ${ }^{17}$. It is clear that adult neurologists need to be trained in these specific areas in order to maintain good clinical skills in the management of complex patients with epilepsy and IDs. The development of Transition Clinics dedicated to transition from paediatric to adult epilepsy service may also favour this process.

Child neurologists identified screening and managing Axis I disorders as the most critical area for their clinical skill development. Mood and anxiety disorders in children are still underestimated and poorly recognised ${ }^{18}$. This is often due to the atypical phenomenology of depression and anxiety in children as compared to adults. It is estimated that up to $50 \%$ of adult patients with a mood or anxiety disorder (not restricted to persons with epilepsy) had an anxiety disorder during childhood ${ }^{19}$, making routine screening crucial for the development of preventative strategies. This is further supported by the American Academy of Child and Adolescent Psychiatry that recommends that children and adolescents should be routinely screened for symptoms of anxiety ${ }^{20}$. In children, the rate of self-reported as compared to parent-reported anxiety is higher, suggesting that it is important to rely on children's self-assessment wherever possible but also to develop specific guidelines of treatment in order not to overmedicate children with non-specific symptoms. 
Finally, this report identified congresses as the preferred educational format of the majority of respondents. More than half the adult neurologists and about one third of child neurologists and psychiatrists chose this format. Review papers and e-learning modules were chosen by a minority ( 1 out of 3). This may be explained by the opportunity to discuss personal cases, ask specific questions or discuss specific clinical scenarios with colleagues.

The results of this survey highlight a number of limitations. First, the limited number of respondents reflects the still limited interest of epileptologists in the psychiatric comorbidities of epilepsy and thus, these results may be representative of a small subgroup of clinicians who are already interested in this subject. This is further suggested by the high rate of clinicians stating that they routinely screen for psychiatric disorders in clinic, namely more than half. Since the initial report of Gilliam et al. ${ }^{8}$, showing that only $7 \%$ of neurologists routinely screen for depression, the ILAE has been strenuously working on a number of educational initiatives. These include two series of the VIREPA course on the psychiatric aspects of epilepsy, the dissemination of easy to use screening instruments for epileptologists (i.e. the NDDIE), the Latin American Summer School for Epilepsy dedicated one edition just to comorbidities. However, relying only on the results of this survey to state that now half of neurologists screen for psychiatric comorbidities is probably overly optimistic, although it is definitely encouraging.

Second, the majority of respondents are located in Europe, North America and Australia. Although this may be due to language barriers, it is also representative of the still low interest of clinicians in other continents about the psychiatric comorbidities of epilepsy. Epilepsy is still a highly stigmatised condition, and stigma greatly affects the QoL of people with epilepsy, leading to increased anxiety and depression and poor adherence to medication ${ }^{21}$. Unfortunately, even currently, stigma is present in both high-income and resource-poor countries ${ }^{22}$. Stigma is not only responsible for poor QoL but also seems to play a role in mood and anxiety problems in both people with epilepsy and their caregivers. Perceived stigma is also responsible for increased rates of aggressive behaviour associated with depression and anxiety ${ }^{23}$. In low and middle income countries, $20 \%$ of mothers of children with epilepsy feel stigmatized because of their child's neurological condition ${ }^{24}$ and the caregiver's perception of burden, together with the level of family function, are indirectly correlated with depressive symptoms in people with epilepsy via the mediating effect of caregiver depression ${ }^{25}$. It seems evident, therefore, that one of the future missions of the ILAE Commission of Neuropsychiatry will be to increase the awareness of clinicians in low income countries of the psychiatric comorbidities of epilepsy, and to explore the consequences of this double stigma.

\section{ACKNOWLEDGMENTS AND CONFLICT OF INTEREST}

No conflicts of interest.

\section{REFERENCES}

1. Fisher RS, Acevedo C, Arzimanoglou A, et al. ILAE Official Report: A practical clinical definition of epilepsy. Epilepsia. 2014;55:475-482. 
2. Birbeck GL, Hays RD, Cui X, Vickrey BG. Seizure reduction and quality of life improvements in people with epilepsy. Epilepsia. 2002;43:535-538.

3. Hermann B, Jacoby A. The psychosocial impact of epilepsy in adults. Epilepsy Behav. 2009;15:S26-S30.

4. Bautista RED, Shapovalov D, Saada F, Pizzi M a. The societal integration of individuals with epilepsy: Perspectives for the 21st century. Epilepsy Behav. 2014;35C:42-49.

5. Lin JJ, Mula M, Hermann BP. Uncovering the neurobehavioural comorbidities of epilepsy over the lifespan. Lancet. 2012/10/02 ed. 2012;380:1180-1192.

6. Tellez-Zenteno JF, Patten SB, Jette N, Williams J, Wiebe S. Psychiatric comorbidity in epilepsy: a population-based analysis. Epilepsia. 2007/07/31 ed. 2007;48:2336-2344.

7. Covanis A, Guekht A, Li S, Secco M, Shakir R, Perucca E. From global campaign to global commitment: The World Health Assembly's Resolution on epilepsy. Epilepsia. United States; 2015;56:1651-1657.

8. Gilliam FG, Santos J, Vahle V, Carter J, Brown K, Hecimovic H. Depression in epilepsy: ignoring clinical expression of neuronal network dysfunction? Epilepsia. 2004;45 Suppl 2:28-33.

9. Kerr MP, Mensah S, Besag F, et al. International consensus clinical practice statements for the treatment of neuropsychiatric conditions associated with epilepsy. Epilepsia. 2011/10/01 ed. 2011;52:2133-2138.

10. Mula M, ludice A, La Neve A, et al. Validation of the Italian version of the Neurological Disorders Depression Inventory for Epilepsy (NDDI-E). Epilepsy Behav. 2012/06/02 ed. 2012;24:329-331.

11. Metternich B, Wagner K, Buschmann F, Anger R, Schulze-Bonhage A. Validation of a German version of the Neurological Disorders Depression Inventory for Epilepsy (NDDI-E). Epilepsy Behav. 2012/11/17 ed. 2012;25:485-488.

12. Tadokoro Y, Oshima T, Fukuchi T, Kanner AM, Kanemoto K. Screening for major depressive episodes in Japanese patients with epilepsy: validation and translation of the Japanese version of Neurological Disorders Depression Inventory for Epilepsy (NDDI-E). Epilepsy Behav. 2012/09/18 ed. 2012;25:18-22.

13. Di Capua D, Garcia-Garcia ME, Reig-Ferrer A, et al. Validation of the Spanish version of the Neurological Disorders Depression Inventory for Epilepsy (NDDI-E). Epilepsy Behav. 2012/07/13 ed. 2012;24:493-496.

14. Brandt C, Labudda K, Illies D, Schöndienst M, May TW. [Rapid detection of a depressive disorder in persons with epilepsy. Validation of a German version of the NDDI-E]. Nervenarzt. 2014;85:1151-1155.

15. Thomson AE, Calle A, Fontela ME, et al. Screening of major depression in epilepsy: The Neurologic Depression Disorders Inventory in Epilepsy-Spanish version (Argentina). Epilepsia. 2014;55:331-334.

16. Reilly C, Atkinson P, Das K, Chin R. Neurobehavioral Comorbidities in Children With Active Epilepsy: A Population-Based Study. Pediatrics. 2014;133:1586-03.

17. Ettinger AB, Ottman R, Lipton RB, Cramer JA, Fanning KM, Reed ML. Attention- 
deficit/hyperactivity disorder symptoms in adults with self-reported epilepsy: Results from a national epidemiologic survey of epilepsy. Epilepsia. 2015;56:218-224.

18. Jones JE. Treating anxiety disorders in children and adolescents with epilepsy: What do we know? Epilepsy Behav. 2014. p. 137-142.

19. Kim-Cohen J, Caspi A, Moffitt TE, Harrington H, Milne BJ, Poulton R. Prior juvenile diagnoses in adults with mental disorder. Arch Gen Psychiatry. 2003;60:709-717.

20. Connolly SD, Bernstein $\mathrm{G}$ a. Practice parameter for the assessment and treatment of children and adolescents with anxiety disorders. J Am Acad Child Adolesc Psychiatry. 2007;46:267283.

21. Buck D, Jacoby A, Baker GA, Chadwick DW. Factors influencing compliance with antiepileptic drug regimes. Seizure. 1997;6:87-93.

22. de Boer HM, Mula M, Sander JW. The global burden and stigma of epilepsy. Epilepsy Behav. 2008;12:540-546.

23. Seo J-G, Kim J-M, Park S-P. Perceived stigma is a critical factor for interictal aggression in people with epilepsy. Seizure. 2015;26:26-31.

24. Elafros M a., Bowles RP, Atadzhanov M, et al. Reexamining epilepsy-associated stigma: validation of the Stigma Scale of Epilepsy in Zambia. Qual Life Res. 2015;24:1483-1489.

25. Han SH, Kim B, Lee SA, Korean Qo L in ESG. Contribution of the family environment to depression in Korean adults with epilepsy. Seizure. BEA Trading Ltd; 2015;25:26-31. 
Table 1. List of countries that participated in the survey (in alphabetical order).

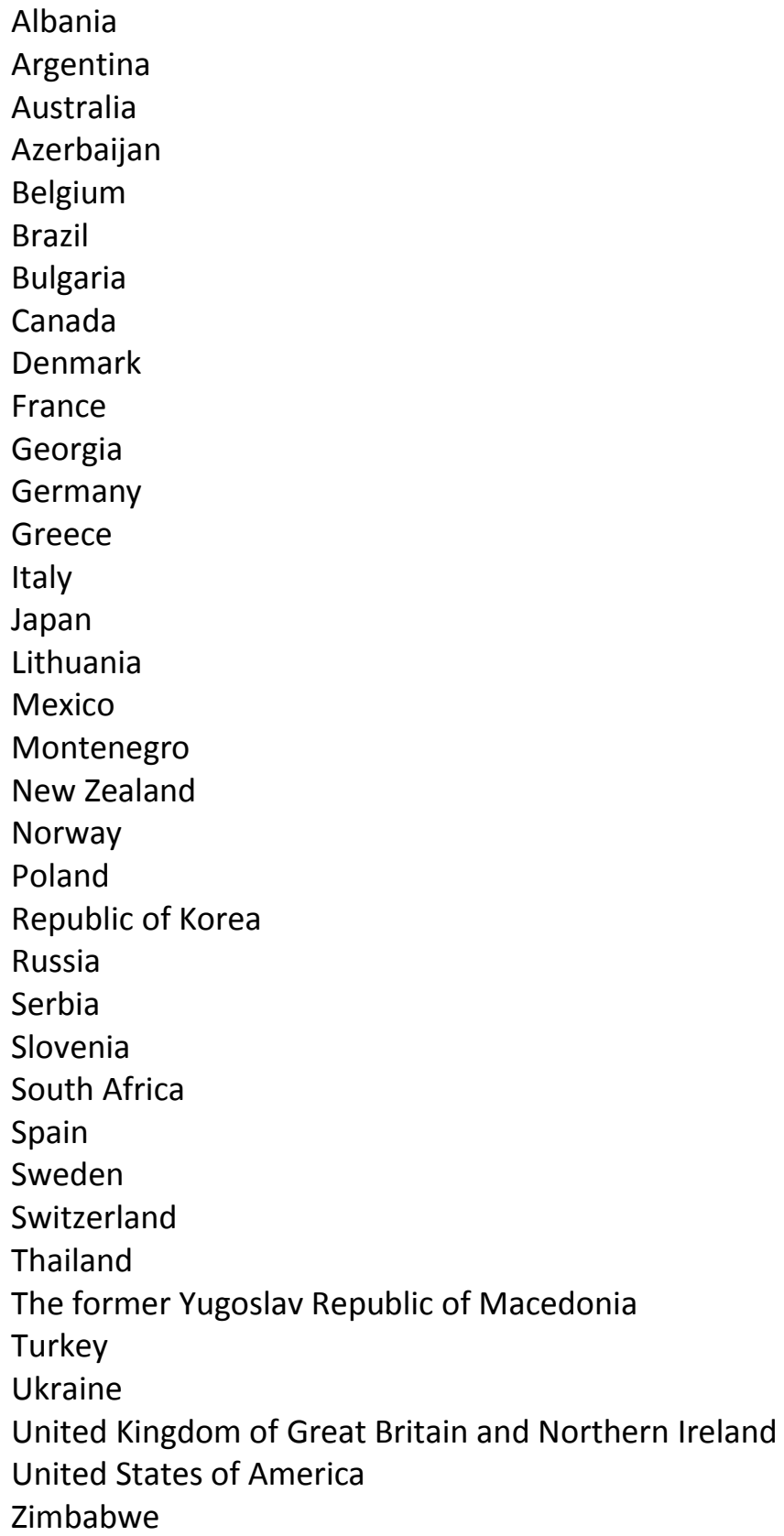


Table 2. Profile of respondents.

\begin{tabular}{|c|c|}
\hline \multirow{2}{*}{ Gender } & \multirow[t]{2}{*}{$\mathrm{N}=\mathbf{2 1 1}$} \\
\hline & \\
\hline Male & $52.4 \%$ \\
\hline Female & $47.6 \%$ \\
\hline \multicolumn{2}{|l|}{ Age } \\
\hline $25-34$ & $10.5 \%$ \\
\hline $35-44$ & $24.4 \%$ \\
\hline $45-54$ & $34.9 \%$ \\
\hline $55-64$ & $20.6 \%$ \\
\hline $65-74$ & $9.1 \%$ \\
\hline$>75$ & $0.5 \%$ \\
\hline \multicolumn{2}{|l|}{ Clinical role } \\
\hline Adult neurologist/Epileptologist & $51 \%$ \\
\hline Child neurologist/Epileptologist & $14.7 \%$ \\
\hline Psychiatrist & $16.7 \%$ \\
\hline Child psychiatrist & $6.2 \%$ \\
\hline Neuropsychiatrist & $5.7 \%$ \\
\hline $\begin{array}{l}\text { Others (i.e. neuropsychologist, epilepsy nurse, mental health nurse, } \\
\text { neuropathologist) }\end{array}$ & $5.7 \%$ \\
\hline \multicolumn{2}{|l|}{$\begin{array}{l}\text { Is there a psychiatrist or a psychologist dedicated to patients with epilepsy in } \\
\text { your centre? }\end{array}$} \\
\hline Yes both & $33.8 \%$ \\
\hline Only a psychologist & $11.4 \%$ \\
\hline Only a psychiatrist & $15.7 \%$ \\
\hline None of them & $39.1 \%$ \\
\hline \multicolumn{2}{|l|}{ Do you routinely screen for psychiatric problems during your epilepsy clinic? } \\
\hline Yes (Adult neurologist) & $56.6 \%$ \\
\hline Yes (Child neurologists) & $54.8 \%$ \\
\hline \multicolumn{2}{|l|}{$\begin{array}{l}\text { Are you reluctant about prescribing antidepressants/antipsychotics in } \\
\text { patients with epilepsy? }\end{array}$} \\
\hline Yes always & $25.5 \%$ \\
\hline Only for antidepressants & $4.8 \%$ \\
\hline Only for antipsychotics & $19.7 \%$ \\
\hline I have no problems & $50.0 \%$ \\
\hline
\end{tabular}


Figure legends.

Figure 1. Self-perceived knowledge and level of confidence in managing psychiatric comorbidities of epilepsy in the total sample (A), among child neurologists (B), adult neurologists (C) and psychiatrists/neuropsychiatrists (D).

A.

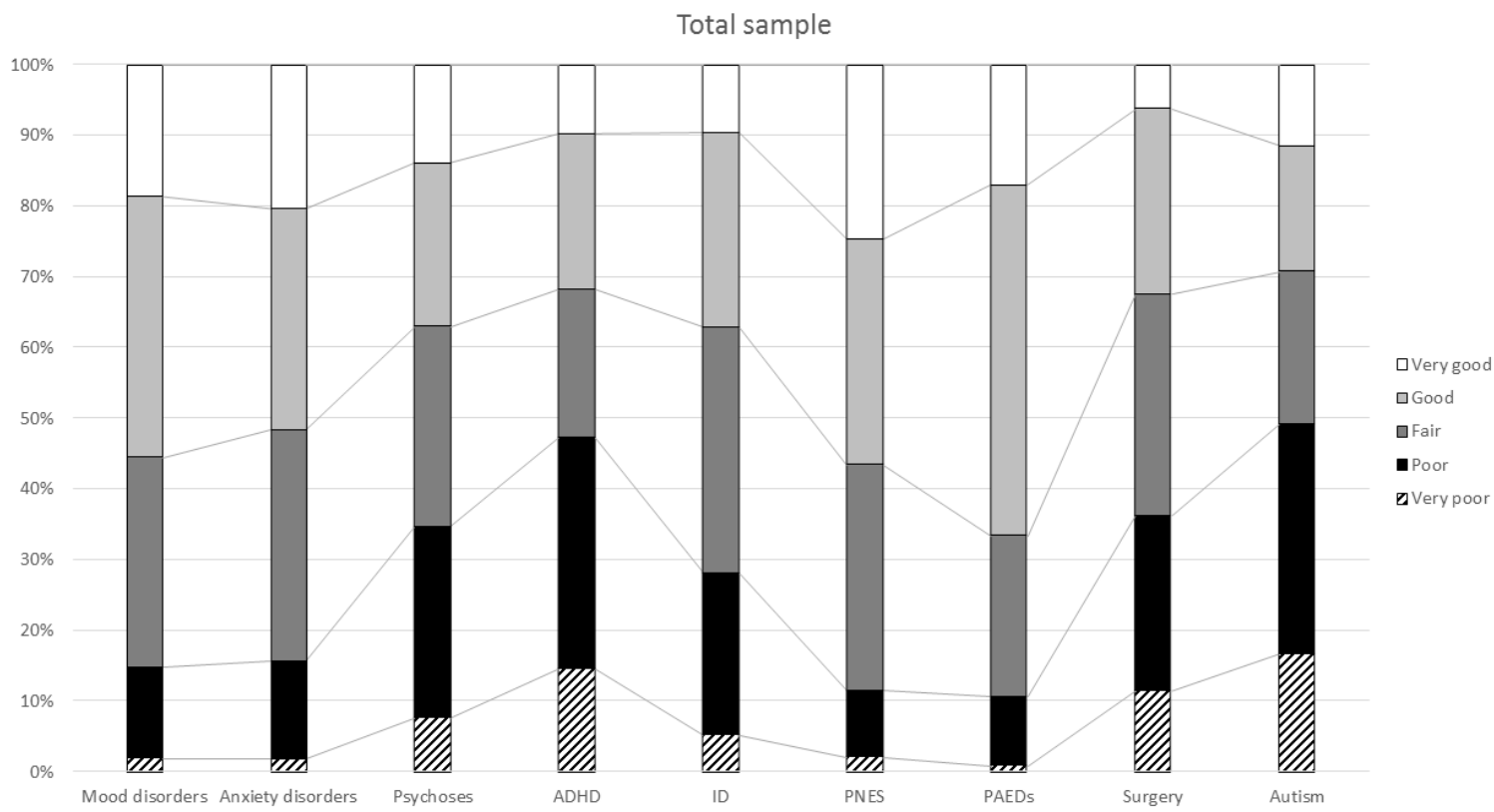

B.

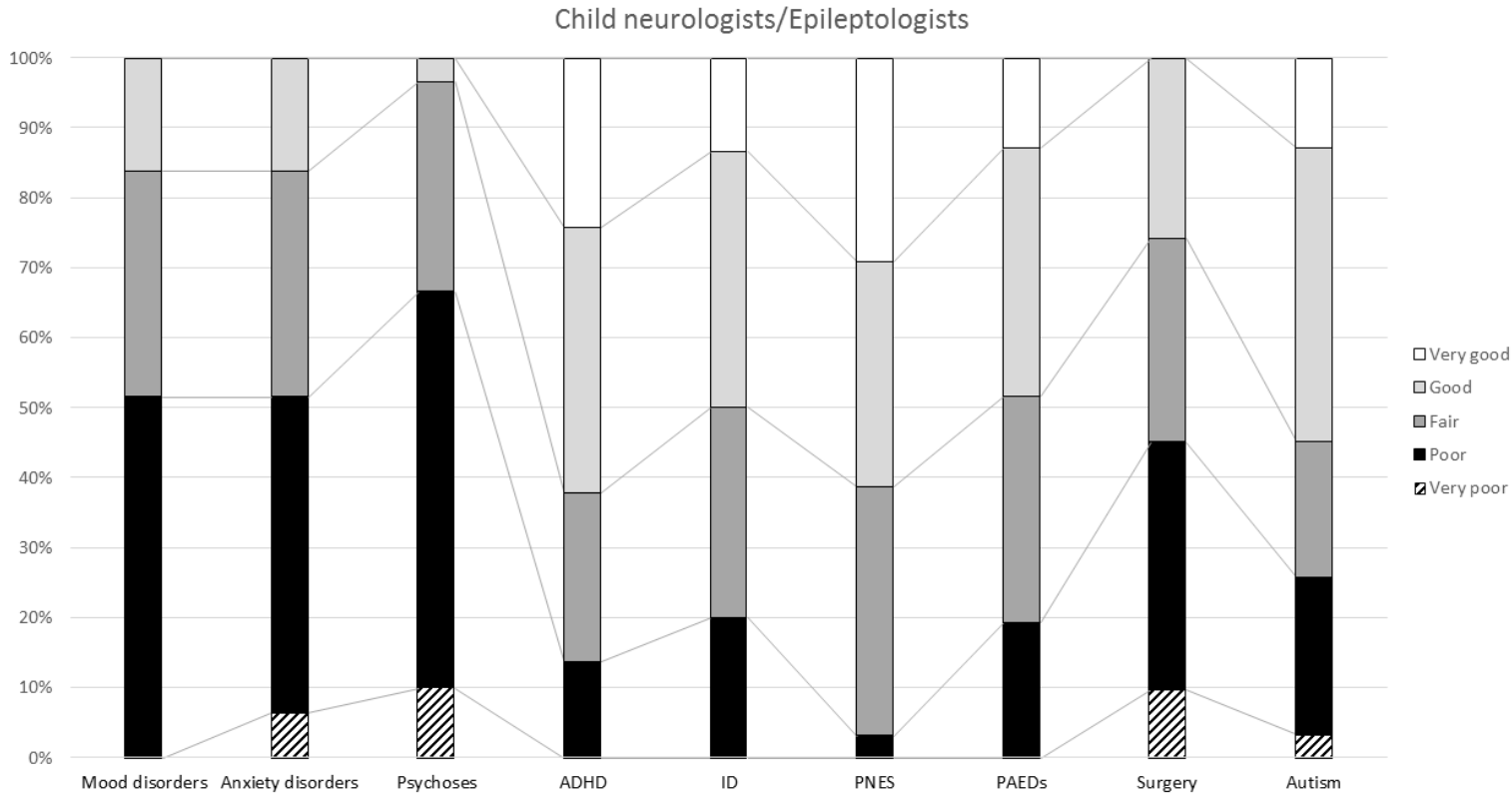


c.

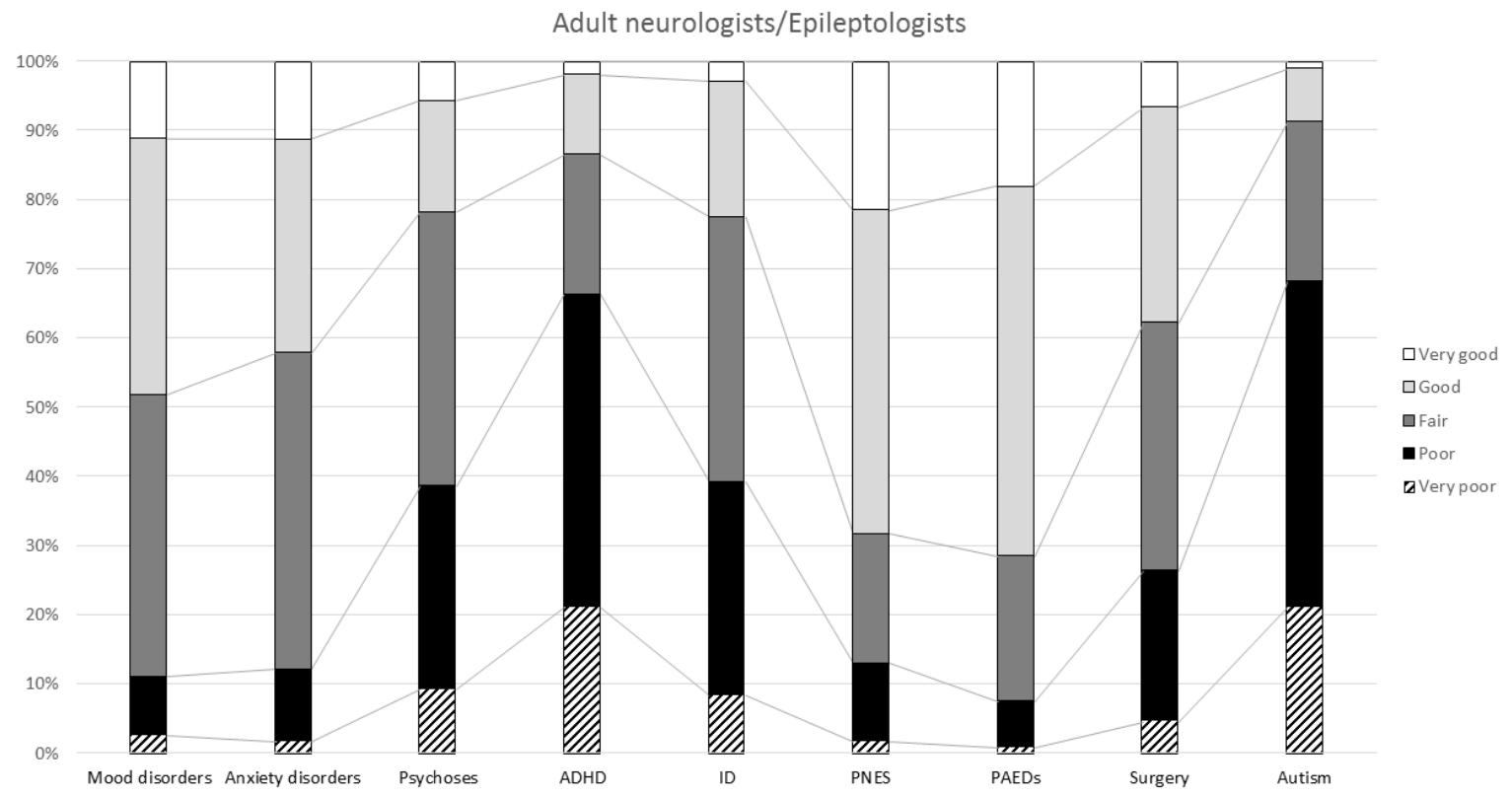

D.

Psychiatrists/Neuropsychiatrists

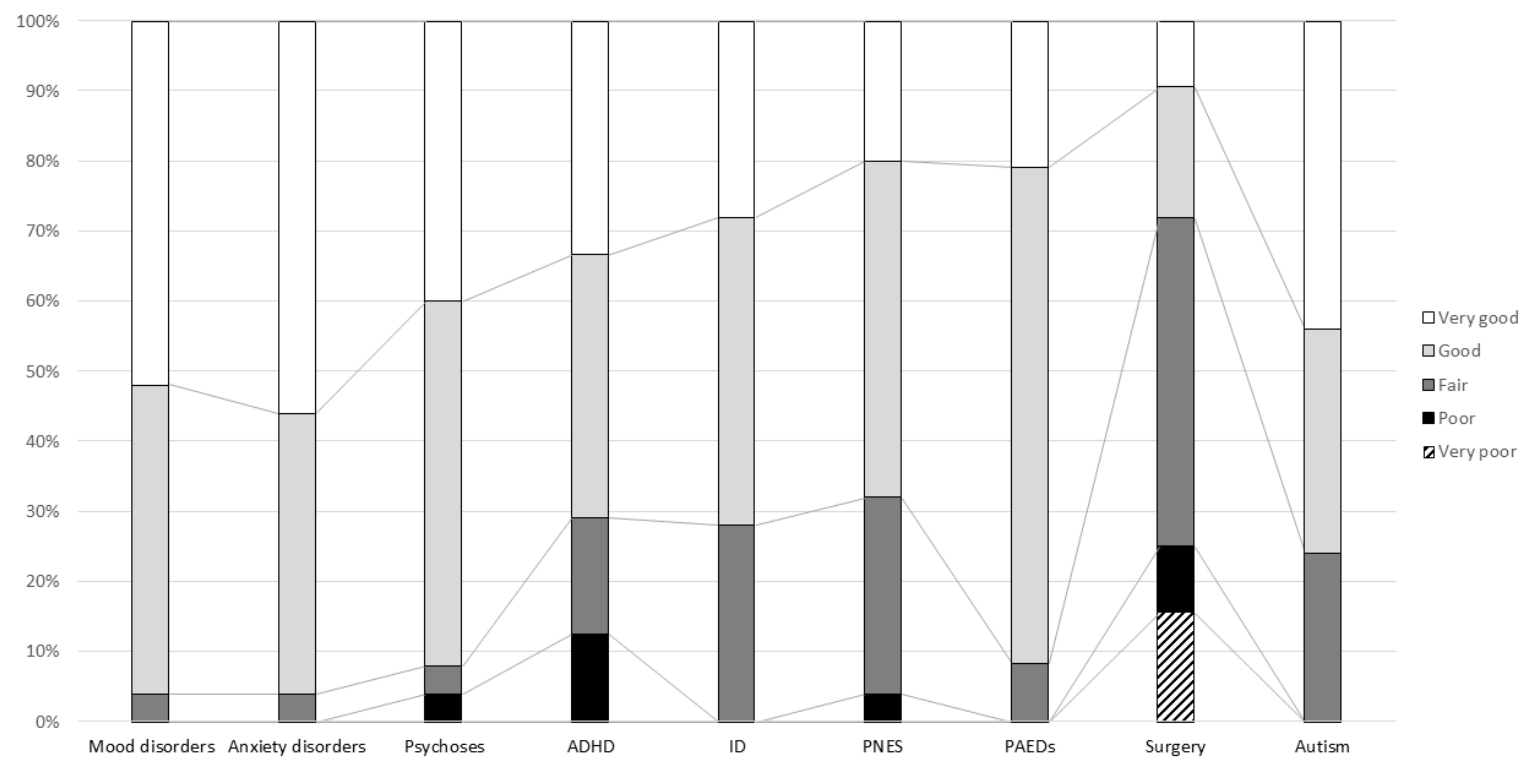


Figure 2. Clinical skills perceived as most important in managing the psychiatric comorbidities of epilepsy.

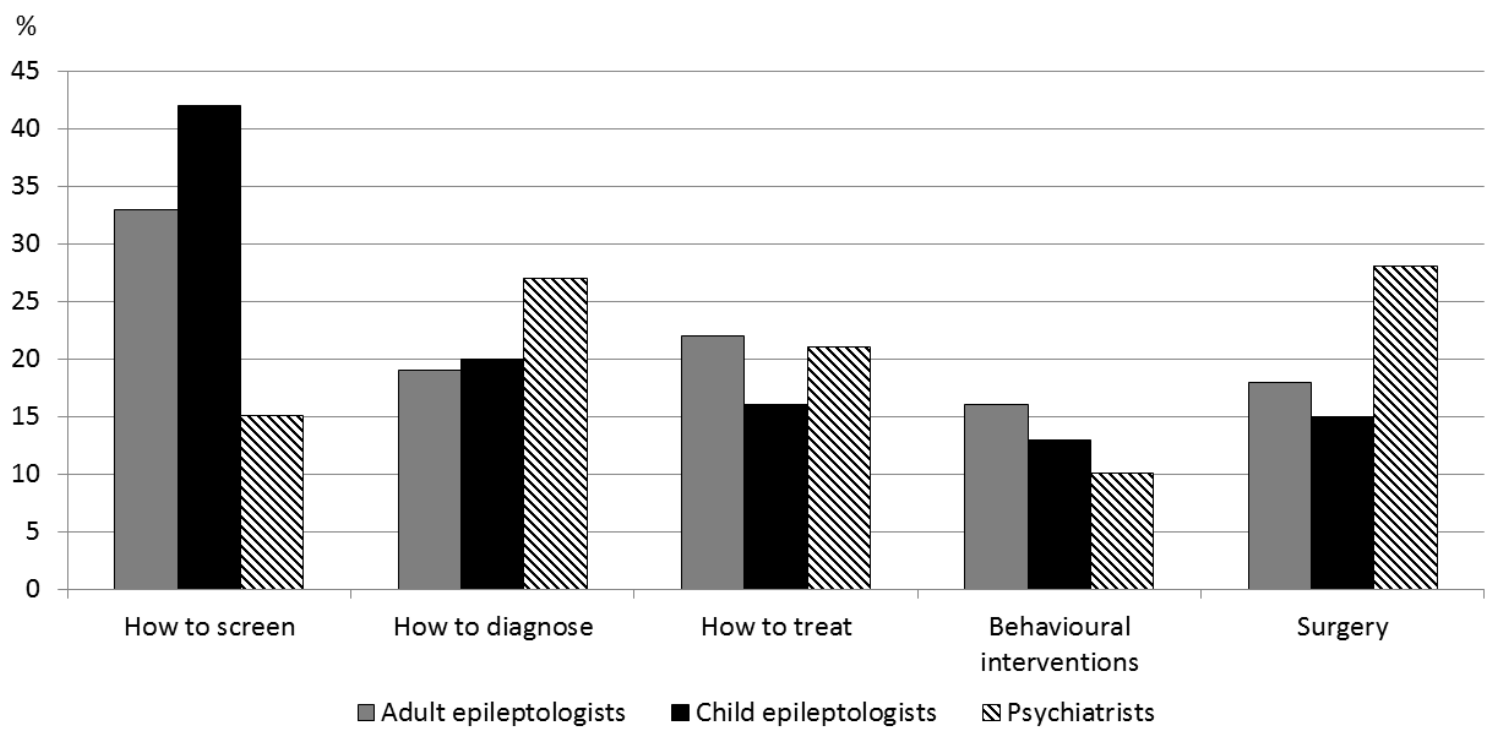




$$
\overline{0}{ }^{\circ}
$$

